\title{
Intellectual and social critique: The role of the South African Journal of Science
}

Over more than a century, since 1905, in various formats and published by different organisations, the content of the South African Journal of Science (SAJS) has reflected the state of scientific thinking in South Africa and provided a platform for multiple voices from its scholarly community.

In keeping with standard practice followed by numerous scholarly journals, the SAJS has a short 'Front Section' containing a variety of articles that, unlike the main research articles in the journal, are not normally peer reviewed. Their purpose is to provide a space for discussion, debate and critique on topical matters relating to science in South Africa.

In terms of ASSAf policy, every submission is subject to a signed legally binding Publishing Agreement that, inter alia, obliges the author to warrant that the manuscript does not contain any unlawful statements or content; does not contain defamatory material; is not in violation of any rights of privacy or any other rights of third persons; if reporting on research involving human or non-human vertebrates, the research meets the highest reporting standards and has been approved by an institutional ethics committee.

Following international best practice, the SAJS encourages robust scholarly debate by accepting and publishing rebuttals and responses from academic peers to published (peer-reviewed) articles as well as to material that is published in the Front Section (currently not formally peer reviewed). The convention is that these are published in the following issue of the Journal together with the original author's response.

One of the Front Section categories is that of 'Commentary': 'Commentaries come in a variety of forms, but they are most often views regarding scientific challenges or opportunities that have arisen out of research experiences. Commentaries can, however, also present the summarised results of research projects, or comments on such research findings, that have direct policy implications and/or immediate social value. Commentaries of a similar or related nature may also be considered.'

The publication of a Commentary in the South African Journal of Science (Volume 116 5/6) by UCT Professor Nicoli Nattrass, entitled Why are black South African students less likely to consider studying biological sciences? elicited many fervent responses from readers. In the interest of fair scholarly discourse and the importance of the matter, we are enabling wide participation by publishing this unprecedented special issue. Every formal response to the Commentary received by the SAJS has been included together with a reply by Prof. Nattrass. All material in this special issue is subject to the standard publishing policies of the SAJS but has not been limited in length.

However, the Editorial Advisory Board of the SAJS has noted the critical responses related specifically to the 'Commentary' section of the Journal. We acknowledge that the current guidelines pertaining to the 'Commentary' section need to be reviewed and, if required, be changed, specifically in regard to what necessitates peer review.

Hence, the Editorial Advisory Board has taken the decision to reconsider the existing guidelines for categories of the Front Section. We will make an announcement regarding this matter in the coming months.

We express our continued commitment to publish research of high quality in line with internationally acceptable norms and with particular attention to ensure that published work does not discriminate or cause harm. We also welcome constructive opinion as to how we might improve our endeavours in this regard.

This episode reflects an important moment in the longer history of the SAJS at a time of 
changing values. Our Statement of 11 June 2020 expressed the hope that this compilation of articles - the original article, the rebuttals and the author's response-will perform an important and useful educational function in universities as well as in our broader society.

Prof. Jane Carruthers, Editor-in-Chief Prof. Johann Mouton, Chair: Editorial Advisory Board

\section{HOW TO CITE:}

Carruthers J, Mouton J. Intellectual and social critique: The role of the South African Journal of Science. S Afr J Sci. 2020;116(special issue), Art. \#8584, 2 pages. https://doi.org/10.17159/sajs.2020/8602 